\title{
Investigação Científica e Tecnológica e a Construção da Nova Aliança
}

\section{Introdução}

No $50 .^{\circ}$ aniversário da Academia Pontifícia das Ciências, o Papa João Paulo II dizia:

"A investigação metódica em todos os campos do saber, se está realizada de uma forma autenticamente científica $e$ conforme às normas morais, nunca será contrária à fé porque as realidades, profanas e as da fé, têm a sua origem no mesmo Deus. Mas seria errado entender esta autonomia das realidades terrestres como se elas nâo dependessem de Deus e como se o homem pudesse dispor delas sem referência ao Criador» [1].

Poder-se-á, então, induzir que a ciência entra em crise quando se reduz a um modelo puramente utilitário ou a um instrumento técnico de domínio.

Entretanto, do que não há dúvida é que, nos dias que passam, se observa um progresso prodigioso da Ciência e a sua influência sobre o espírito e o comportamento do homem moderno é, cada vez mais, vasta e profunda.

\section{O homem de ciência, os seus problemas hoje e o sentido do sobrenatural}

A Ciência para ser acompanhada e compreendida no seu desenvolvimento por aqueles que a praticam exige, hoje, total empenhamento como o reconheceu, por exemplo, Teilhard de Chardin que, porque a praticava, soube descobrir nela o estímulo necessário para aprofundar o efeito da verdade científica na compreensão do sobrenatural. $\mathrm{O}$ que acontece é que a ciência, através dos novos modelos e linguagens a eles associados, fornece nova simbologia à expressão do religioso. Pense-se, por exemplo, que, nos fins dos século XIX, os físicos, um pouco na linha dos positivistas, acreditavam que tudo de essencial estava descoberto. Aliás, já Laplace tinha dito a propósito do triunfo da mecânica: «não haverá dois Newton pois só havia um mundo para descobrir» [2]. Por aqui se pode compreender que os físicos, no final do século XIX, considerassem que a Física tinha atingido os seus limites, o que, incontestavelmente, poderia ser considerado como penalizante para toda a reflexão que parecesse ameaçar a ambição de uma concepção «objectiva» da natureza, isto é, ameaçar a possibilidade de a física tender, ainda que de forma indefinida, para um ponto de vista sobre ela (natureza) essencialmente análogo ao que teria um Deus criador, por razões de se confrontar com pro- blemas dos infinitamente grandes ou dos infinitamente pequenos.

No entanto, na linha de pensamento de Formosinho a investigação científica vem demonstrar que «as fronteiras do conhecimento científico não são herméticas, nem rígidas. Por isso quando a ciência se debruça sobre a natureza, perto dos limites físicos, começa a transmitir perspectivas diferentes das que o mundo do "quotidiano" permitiu estabelecer, mas que se aproximam do sentido mais profundo da matéria da vida do homem, revelados pela religiâo" [3].

Neste contexto refiram-se exemplos, alguns deles também mencionados pelo mesmo Formosinho:

A separação entre o «eu» e o mundo, uma das essências da filosofia de Descartes, acentua-se no limite da micro-física, tendo em conta o princípio da incerteza de Heisenberg e a visão probabilística da mecânica quântica que surgem como resultado do contacto do homem com o micro-cosmos; a distinção entre espaço e tempo, fundamental em Kant, esbate-se com a teoria da relatividade de Einstein, onde a descoberta do tempo como a quarta dimensão cria relação diferente entre observador e acontecimento observado. Refira-se que, nos termos desta teoria, a sequência de dois acontecimentos, A e B, pode ser apercebida por ordem inversa quando esses acontecimentos são observados por dois observadores distintos. Não era e não é certamente, este o sentido das leis da dinâmica clássica quando se referem, por exemplo, ao estudo dos fenómenos periódicos ou dos movimentos dos astros, o que é feito com concisão e elegância admiráveis, como observa Prigogine «tais fenómenos ignoram a direcção do tempo e são repetição infinita do passado no futuro" [4]. A questão fundamental é a de saber qual verdade é que corresponde à vocação como ciência ou se, pelo contrário, podem ser definidos novos modelos e formulações que ultrapassam o quadro conceptual da ciência clássica, mesmo prolongada pela mecânica quântica e pela relatividade.

Desenha-se, porventura, um novo tipo de unidade do conhecimento científico quando o homem se confronta com o microcosmos, no limite das grandes velocidades das pequenas partículas, onde causa e efeito perdem o seu significado clássico e os acontecimentos passam a ser definidos em termos probabilísticos.

No fundo gera-se uma aparente oposição entre o determinismo da linguagem clássica e o carácter aleatório da linguagem moderna quanto à previsão do acontecimento futuro.

${ }^{\text {a }}$ Departamento de Química, Faculdade de Ciências, Universidade de Lisboa. 
O mesmo tipo de problema surge quando se pretende descrever o mundo dos «infinitamente grandes», das grandes partículas ou das galácticas onde a causalidade tem novos contornos (quais?), quando, para a descrição do mundo físico, o homem tem de se socorrer do princípio da inflação quântica e esse mesmo homem se confronta com a descrição de um universo que ultrapassa, em termos descritivos, a sua capacidade mental. Quais os modelos que o homem pode compreender em sistemas como estes? Porventura, aqueles que a temporalização da geometria se substitua à geometrização do tempo. Estamos perante a expansão do Universo, a fuga das galácticas de que a Lei de Hubble define a evidência observável que faz do mundo que estudamos não uma verdade eterna, mas um simples instante da evolução cósmica. Referindo, novamente, Prigogine «... desta vez é a concepção de um Universo longe do equilíbrio que penetra na cosmologia" [5].

A verdade é que estes dois novos tipos de relações com o microcosmos e com o macrocosmos, respectivamente, tiraram grande parte dos fundamentos às razões de alguns positivistas. Por outro lado ou simultaneamente, suscitaram que Deus pudesse ser expresso por um novo número de metáforas e de parábolas. Referindo novamente, Teilhard de Chardin «O mistério da fé e a interrogaçāo da transcendência subsistem, mas a linguagem com que se exprimem pode assumir uma nova modernidade» [6].

\section{A época de mudança que vivemos e outras épocas de mudança}

Vive-se uma época de mudança muito intensa, particularmente depois da segunda Guerra Mundial, em que as descobertas científicas e tecnológicas se sucedem a ritmo vertiginoso com consequências ao nível social e cultural que vão transformando os modos de vida do homem, criando-lhe novas aspirações e dando novos contornos no relacionamento com outros homens. Adeante, este ponto será mais desenvolvido e exemplificado.

No entanto, muitos homens tiveram experiências semelhantes através dos tempos, particularmente, nas épocas de crise, e em épocas revolucionárias. Do ponto de vista científico são, neste contexto, de referir épocas como a das catedrais, no século XI e XII, que centralizaram, na cidade, a vida administrativa e cultural e, durante a qual, as novas concepções arquitectónicas influenciaram diferentes artes e provocaram importantes desenvolvimentos científicos no campo da geometria, das ciências económicas, etc.; a Renascença que abriu ao homem a cultura clássica e se fez como que uma redescoberta da beleza do profano para melhor ajudar o homem a descobrir o Criador na linha, um pouco, do que já tinha sido sentido, dois ou três séculos atrás, por São Francisco de Assis; os séculos XVII, XVIII e XIX durante os quais o método científico, de base experimental rigorosa, permitiu ir definindo modelos matemáticos progressivamente mais adequados à descrição da realidade. No fundo, situações como estas, ou outras que não ficaram, porventura, tão marcadas na história da humanidade, reflectem, de forma mais ou menos acentuada, o impulso de buscar a verdade oculta e de a investigar não apenas como imperativo de corresponder a uma vocação específica e a uma atitude ética de melhor compreender o sentido da vida humana. É, tam- bém, nesta base, que se pode - e deve - encontrar a força da religião, da ciência e definir os fundamentos do que se entende por ideologia.

Na verdade muitos homens, envolvidos no estudo da ciência, sentiram a perturbação, sem dúvida apaixonante, de se encontrarem no meio de um enigma, enigma esse que tem levado muitos deles a interrogarem-se sobre o sentido do seu trabalho, da sua vida e do Universo que os rodeia. Sem que adira, em parte, às reflexões de Louis Pasteur, entendo útil referi-las: «Vós colocais a matéria antes da vida; mas quem nos diz que o progresso do conhecimento nâo obrigará a admitir - um dia - que é a vida que existe desde toda a eternidade, mesmo antes da matéria? » [7].

\section{A ciência e a técnica devem dar razōes de esperança}

Nos nossos dias, não podemos deixar de constatar que o esforço de construção e aperfeiçoamento do mundo em que vivemos, tem levado à situação em que o império da ciência e da técnica é indiscutível, sobretudo nas regiões do globo economicamente mais favorecidas sem que, em muitos casos, o social acompanhe o tecnológico. No entanto, este e outros aspectos dele derivados devem ser corrigidos em termos de construção de um mundo novo onde se tenha em vista conseguir boa qualidade de vida para todos, sobretudo, na justa distribuição das riquezas e onde o conforto que as descobertas científicas e técnicas proporcionam, sirva, também, para ajudar os homens menos protegidos pela sorte. Estes são conceitos e propósitos que deverão, tendencialmente, ser realizados à escala planetária para que, de facto, todos os homens possam ir na verdade, pertencendo à mesma comunidade dos filhos de Deus. Sobretudo, no caso dos jovens, eles possam encontrar mais razões de esperança no mundo que se vai construindo.

$\mathrm{O}$ que acontece é que, em termos técnicos, a realização daqueles objectivos vai sendo facilitada. Basta lembrarmonos, por exemplo, dos numerosos e aperfeiçoados progressos dos meios de comunicação que hoje são postos à disposição do homem e que muito podem ajudar, de forma rápida e eficaz, a colaboração entre gentes das mais afastadas partes do mundo. A este propósito refere a Constituição Apostológica Gaudium et Spes: «O mundo actual apresenta-se simultaneamente poderoso e débil, capaz do melhor e do pior, tendo patente diante de si o caminho da liberdade ou da servidāo, do progresso ou da regressão, da fraternidade ou do ódio e o homem torna-se consciente de que a ele compete dirigir as forças que suscitou e que tanto o podem esmagar como servir. Por isso se interroga a si mesmon [8].

\section{O desenvolvimento científico e a necessidade de métodos dinâmicos de informação e documentaçâo}

É vulgar dizer-se, com alguma razão, que ao ritmo a que se processa a educação moderna ou pela forma como se preparam os cientistas e os técnicos de hoje, que não se encontra oportunidade ou tempo para investigar os alicerces filosóficos em que assentam os métodos e as técnicas que vão sendo utilizadas. Que não há, inclusivamente, tempo para, no campo específico de cada um, se ler tudo o que, de essencial, se vai publicando, apesar da facilidade de acesso às fontes, 
desde que se disponha de métodos dinâmicos de informação e de documentação. Nestas circunstâncias, são cada vez mais sofisticados os meios que as novas técnicas computacionais e de telecomunicações oferecem aos centros de documentaçâo científica e técnica, meios esses que permitem um rápido e seleccionado contacto com as enormes fontes bibliográficas acumuladas e dispersas pelo mundo.

A utilização deste tipo de facilidades é, hoje, um factor de decisão fundamental que, infelizmente, não é partilhado por grande parte da população mundial, particularmente aquela que se encontra nas regiões mais pobres onde abunda o subdesenvolvimento económico e o analfabetismo. Associado a tal podem criar-se situações como, por exemplo, a da transferência de tecnologias, feita, em muitos casos, em condições de aviltante exploração e de dependência permanente dos mais pobres em relação aos mais ricos.

Em Portugal, embora só há relativamente pouco tempo tenham começado a ser feitos investimentos com algum significado nas áreas da informática e das telecomunicações, o que acontece é que é uma das áreas mais promissoras na qual se têm revelado em número assinalável - embora insuficiente - bons investigadores de reconhecido talento. Tal não pode deixar de ser referido como sinal de esperança dada a sua importância para a planificação da economia e do desenvolvimento científico e cultural.

De notar, ainda, a importância da informática e da computação, como instrumento imprescindível, na ajuda à coordenação e orientação de projectos de base interdisciplinar, através da qual as capacidades prospectivas de diferentes investigadores podem ser ampliadas e serem facilitadas a análise e o estudo de diferentes problemas e métodos. Como aplicação, ainda, do que se acaba de referir, a especificidade do fenómeno biológico, a génese da noção de informação, os conhecimentos de estrutura e de ordem estão hoje no centro de todo um vasto avanço científico que utiliza e necessita de todo aquele tipo de colaboração.

\section{Alguns aspectos da evoluçāo científica depois da $2^{\text {a }}$ Guerra Mundial}

Como pensar, por exemplo, que teria sido possível, sem o apoio da informática, a resolução dos diferentes problemas que foram surgindo na sucessão dos acontecimentos que permitiu definir a estrutura, de base helicoidal, do DNA, o material genético fundamental. Tratou-se de um dos episódios que mais contribuiu para o progresso da humanidade depois da $2^{\mathrm{a}}$ Guerra Mundial e para o qual cientistas de diferentes perfis - informáticos, químicos, biológicos, médicos, etc. tiveram papel relevante. Foi, na verdade, um acontecimento singular por um conjunto de razões, das quais a científica não foi a menor. Não há dúvida que esta descoberta de Crick e Watson, com todas as suas implicações biológicas, foi verdadeiramente notável não só por si, como pelo número de investigações que inspirou e continua a inspirar, bem como pela quantidade e diversidade de conhecimentos científicos a que foi necessário recorrer para atingir os objectivos pretendidos. Pense-se no que tem sido - e continua a ser -0 extraordinário desenvolvimento da bioquímica nos últimos trinta ou quarenta anos. Refira-se os, ainda há pouco inimagináveis, resultados nos domínios da engenharia biológica e da manipulação genética em relação à qual muito ainda se pode esperar e, não só no aspecto estritamente científico. Também diferentes investigações, neste domínio, são hoje linhas importantes em escolas universitárias de medicina e de agricultura.

Referindo-se ao relato do acontecimento feito pelo próprio Watson, Sir Lawrence Bragg, prémio Nobel da Física dizia: *Os capítulos em que é descrito o nascer de uma nova ideia sâo de verdadeiro drama. A tensâo sobe e sobe até atingiro climax final. Como em nenhuma outra descoberta com importância verdadeiramente histórica, se pode compreender, como aqui, o drama do investigador, as suas lutas e o triunfo final!...* [9].

No entanto, este é apenas um exemplo do impressionante desenvolvimento científico e tecnológico, depois da $2^{\mathrm{a}}$ Guerra Mundial, o qual se tem processado a tal ritmo que a sensibilidade humana vai perdendo o sentido da sua importância. A verdade é que muitas das consequências das descobertas e das suas aplicações vão influenciando fortemente a nossa forma de viver.

De qualquer modo, a evolução científica tem, quase sempre, contribuído para o bem do homem, pelo menos potencialmente. Por exemplo os biólogos, os químicos e os engenheiros vão criando condições para tornar a Terra mais fértil e os médicos para prolongar a longevidade humana até limites jamais alcançados.

A rapidez e a segurança técnica dos meios de transporte é tal, que já parece um acontecimento longínquo a construção do primeiro avião supersónico; conjuntamente, o avanço nas telecomunicações faz com que a «dimensão» de cada ser humano se alargue, cada vez mais. Materiais desconhecidos, ainda há poucos anos, passaram a incluir-se na tessitura da nossa vida, como, por exemplo, as múltiplas aplicações de polímeros condutores e, ou, conjuntamente com a construção de componentes da indústria eléctrica e electrónica e a dos computadores que tornam o trabalho humano menos significativo, como fonte de energia.

A presença do homem, entretanto, não se confina à dimensão da Terra; novas fronteiras se vão estabelecendo e o homem vai alargando as suas perspectivas e conhecimentos em cada nova viagem espacial. Quem não se recorda da excitação que sentiu quando foi lançado o primeiro «sputnik»; ou quando o homem chegou, pela primeira vez à Lua? Em quanto diminuiu a excitação e a curiosidade dos homens nos tempos que correm quando se referem proezas equivalentes?

Pense-se ainda, em relação às ciências do ambiente, no que se tem avançado sobre o conhecimento do metabolismo dos metais fixados no corpo humano e como tal tem permitido esclarecer pormenores sobre a sua toxicidade. Ou, também, no que se tem avançado nos processos catalíticos em fase líquida como alternativa aos clássicos heterogéneos gás/ /sólido, com as consequências da enorme diminuição da poluição atmosférica. Por exemplo, a pouca divulgação e utilização do fabrico do amoníaco em fase líquida, com muito menor libertação de gases que os clássicos e vulgarizados processos catalíticos de Haber-Bosh com exigência de elevadas pressões e temperaturas.

Sem dúvida que estes avanços no conhecimento humano são consequência, diria inevitável, do aumento de capacidade de controle de acordo, a um lado com a escala e, a outro, com a 
problemática sobre a massa e a energia para já não falar nos níveis do macrocosmos.

Em muitas investigações, fundamentais e aplicadas, que se relacionam com os problemas acima referidos e outros, estiveram e estão envolvidos investigadores portugueses, isto apesar de os investimentos oficiais, nesta área, serem ainda insuficientes, quando comparados com o que acontece, principalmente, em países da nossa área económica e cultural.

Este aspecto parece ser aqui relevante tanto mais que a ciência faz parte do complexo de cultura a partir do qual, em cada geração, os homens tentam encontrar uma forma de coerência intelectual.

\section{A investigação científica, o ensino e a universidade}

No seguimento do que se acaba de referir a investigação científica, além de outras funções, deve ser força motriz do ensino para que este seja ministrado com inspiração e com verdadeiro sentido dos problemas, fazendo os alunos compreender melhor que o que se ensina é possível ser verificado. Sobretudo, que as propostas que se apresentam são passíveis de aperfeiçoamento pela investigação e, evidentemente, na qual os próprios professores, sempre que possível, devem estar envolvidos para serem reconhecidos tanto como promotores do avanço da ciência, como pelo estímulo que dão ao seu cultivo.

$\mathrm{Na}$ Universidade, em particular, a investigação deve polarizar centros de progresso e luz onde a cordialidade, o espírito criativo e o de serviço devem dar as mãos. Em coerência com isso, e por recurso aos seus potenciais científicos, a Universidade deve abrir-se para projectos inter- e multi-disciplinares dos quais resultem ou possam resultar serviços úteis à comunidade dentro e fora dela. No entanto, para que tal aconteça, a Universidade deve estar atenta e aberta para actuar com oportunidade.

A Universidade é, na verdade, um centro privilegiado de juventude onde se desenvolvem projectos de investigação sofisticados. Por isso, deve ser alegre e generosa, com espírito de aventura para corresponder às aspirações dessa mesma juventude que, para não ser frustrada, se deve sentir participante de uma obra comum. Onde as opiniões dos professores possam ser postas em causa e estes aceitem, com humildade, que, mais tarde, os mais jovens passarão a ter ideias, porventura melhores, e mais ajustadas aos tempos futuros.

Falo em a Universidade ser jovem e a isso não posso deixar de associar ideias de paz no que, no concreto, significa desenvolver amizade entre os homens e colaborar, pelas ideias e pela investigação, para que os recursos que a natureza concede com mão largas sejam, pela ciência e pelo trabalho, sempre melhor aproveitados.

\section{A investigaçāo científica, a justiça social e o sentido de Deus}

Ninguém nega o interesse das descobertas científicas. No entanto, em relação a algumas delas, muitos porão em causa a sua importância prática. Por exemplo, para que é que interessará aprofundar mais o conhecimento da estrutura das moléculas, dos átomos e dos núcleos atómicos? ou que a superfície da Terra está continuamente a ser ajustada sob a influência de sistemas de convexão de calor ainda não completamente compreendidos? ou ainda perguntarão quais destas descobertas contribuirão para dar de comer a tantas pessoas de qualquer país sub-desenvolvido, ou para resolver os inúmeros problemas de desemprego também de muitos países?

Estamos longe de poder avaliar a forma como a ciência e a tecnologia, feitas nos anos recentes, ajudaram e beneficiaram o homem e, até certamente, de forma diferenciada de acordo com o próprio desenvolvimento económico dos países. Tal só mostra que muito há a fazer para se conseguir maior justiça social. Por isso, é natural que se ponham questões como estas, particularmente quando se sentem crises como as referidas. No entanto, o trabalho de pesquisa permite ao homem ir conhecendo melhor o mundo em que vive. Nessa medida, esta actividade não pode deixar de ser um bem e a verdade é que muitas investigações - algumas delas enunciadas atrás - permitiram que, de repente, se descobrissem aplicações importantes, não previstas à partida.

A previsão do futuro é, filosoficamente, impossível. Não há forma de se prever como a ciência evolui e quais das interrogações dos homens encontrarão respostas adequadas. Entre estes problemas, também os de fome, de desemprego e outros de natureza social exigem que, sem disfarces ou sofismos, se encarem, para eles, soluçōes progressivamente mais aperfeiçoadas. Especialmente para os jovens.

Cada um de nós, pela simples razão de ser homem, tem por missão, diria mesmo por vocação, conhecer melhor o mundo em que vive e tentar, à sua escala melhorá-lo para um serviço mais perfeito em favor do seu semelhante. Com consciência deste princípio - com criação de maior justiça social - poderá o homem, em espírito fraterno, descobrir as condições de maior liberdade entre os homens.

Neste contexto, não se pode deixar de insistir que a justiça social só se vai conseguindo desde que o avanço tecnológico vá beneficiando, por igual, todas as nações do mundo e que, conjuntamente, o pensamento científico se torne mais solidário e progressivamente mais útil para todos os homens por forma a elevá-lo à possibilidade de a todos aperfeiçoar. Não é, certamente, isto que acontece quando, por exemplo, os países mais ricos do Norte, colocam indústrias de «chave à porta» nos países Africanos e na América do Sul, mantendo-se, entretanto, exagerada dependência tecnológica destes em relação àqueles. Também não é coerente, com este espírito de justiça, a transferência das chamadas indústrias «sujas» (pasta de papel, siderurgias, etc.) do Norte para o Sul para defesa da qualidade de vida daqueles e para tornar possível algum enriquecimento destes à custa de processos que, porventura, não vão ser implantados com todos os cuidados possíveis: tratamento de efluentes industriais, que podem matar as flora e fauna aquáticas locais. Não são claros, também, os casos em que impõem tecnologias, como a do amoníaco, por critérios puramente económicos.

Entendo que, mais importante que isso, importa preservar a vida dentro de um quadro paisagístico e cultural que, não se deixando vencer por um tradicionalismo excessivo, se faça por forma que os desenvolvimentos industriais e económicos tenham em conta a necessidade de participarem na constru- 
ção de uma nova sociedade que, certamente, se deve orientar por padrões de maior frugalidade, por parte dos mais ricos, para melhor compreenderem os mais pobres e com eles se tornarem mais solidários num quadro de maior fraternidade. De qualquer modo acredito que há sempre razões de esperança e essas razões resultam de se poder acreditar na inventividade intrínseca do diálogo científico com a natureza o que nos dá hoje os meios de começar a pensar o tempo, que nós não vivemos na brevidade da existência humana, como uma contradição. Não podemos conceber o pensamento como um monólogo fora do qual não há senão o nada.

A imagem da Natureza, nos limites do que é materiàl, parece levar-nos que a razão refere ao Espírito. É como se na separação entre a física e a metafísica, as leis da matéria pudessem penetrar tanto o mundo da matéria como o mundo do espírito.

A ciência moderna construiu-se sem a hipótese de Deus. No entanto, reportando-me a muito do que referi atrás, acredito que poderá encontrá-lo nos limites do conhecimento e, desta forma, começar a ganhar o sentido da matéria e da vida e a ajudar a restabelecer uma nova aliança com Deus.

\section{Agradecimentos}

A terminar um agradecimento muito amigo pelas sugestões que generosamente me deram aos Professor Sebastião J. Formosinho e Doutores Maria José Ferreira Rebelo e José Alberto Gomes Machado,

\section{Referências}

[1] «Discurso do Papa João Paulo II à Pontifícia Academia das Ciências». Osservatore Romano, 16.XI.1986, pg. 1759.

[2] Rousseau, Pierre, «Histoire de la Science», cap. 7, ed. Arthème Fayard, Paris (1945), referido, também, por Prigogine, ref. [4], pág. 5.

[3] Formosinho, S. J., «A Vida, Propósito ou Acaso?», em publicação.

[4] Prigogine, I. e Stengers, I., «A Nova Aliança», ed. Gradiva, Lisboa (1986), pg. 23 e cap. VIII, pg. 320.

[5] Ref. [4], cap. IX, pg. 332-354.

[6] P. Teilhard de Chardin, «Le Groupe Zoologique Humain», $1^{\mathrm{a}}$ parte, cap. 3, ed. Albin Michel (1956).

[7] Partington, J. R., «A History of Chemistry», vol. 4, ed. MacMillan Press Ltd (1972), pg. 749.

[8] Vaticano II, $7^{\mathrm{a}}$ ed. Secretário Nacional do Apostolado da Oração (1976), Constituição Gaudium et Spes, pg. 343.

[9] Watson, J. D., «The Double Helix», ed. Signet Book (1969), pg. vii.

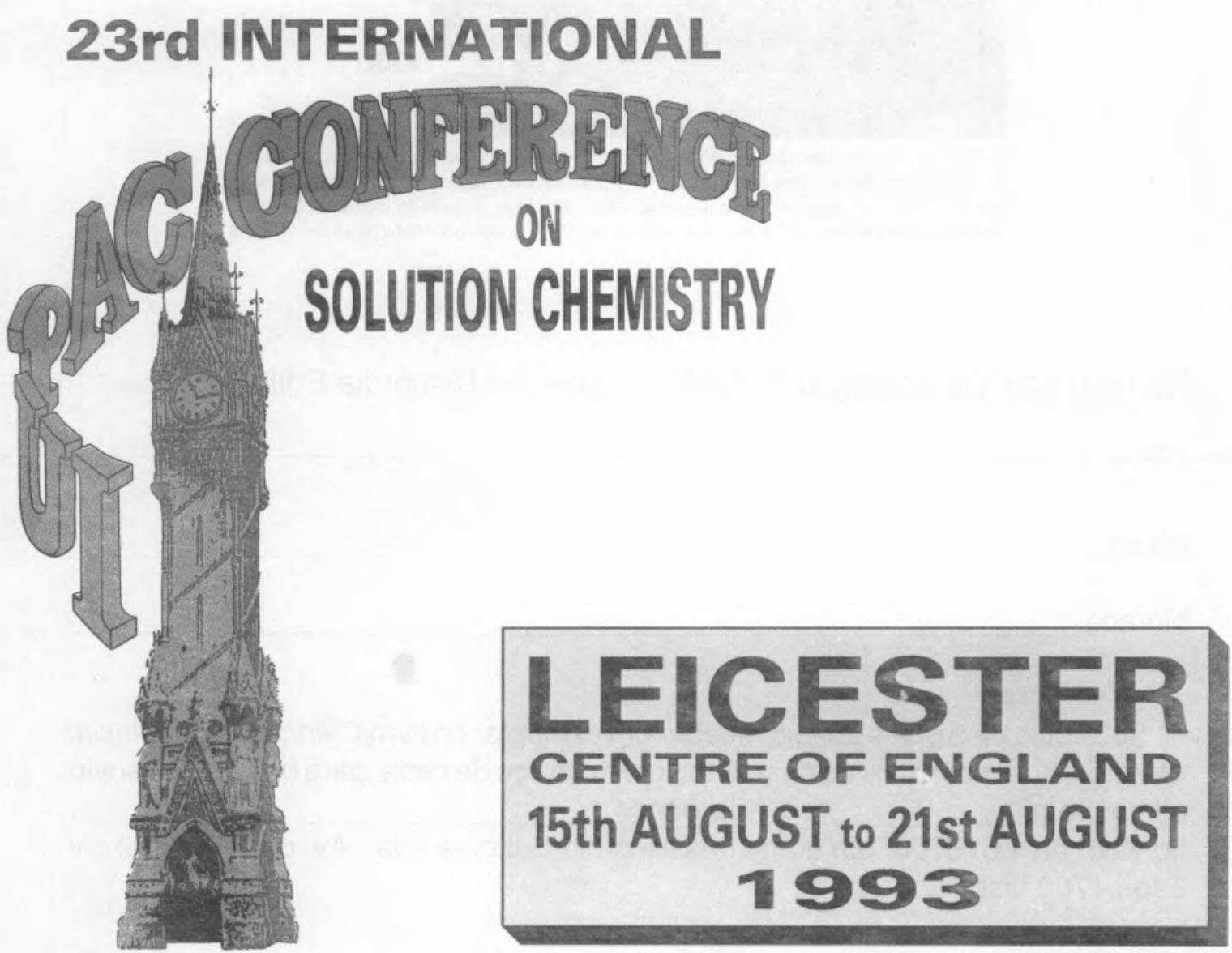




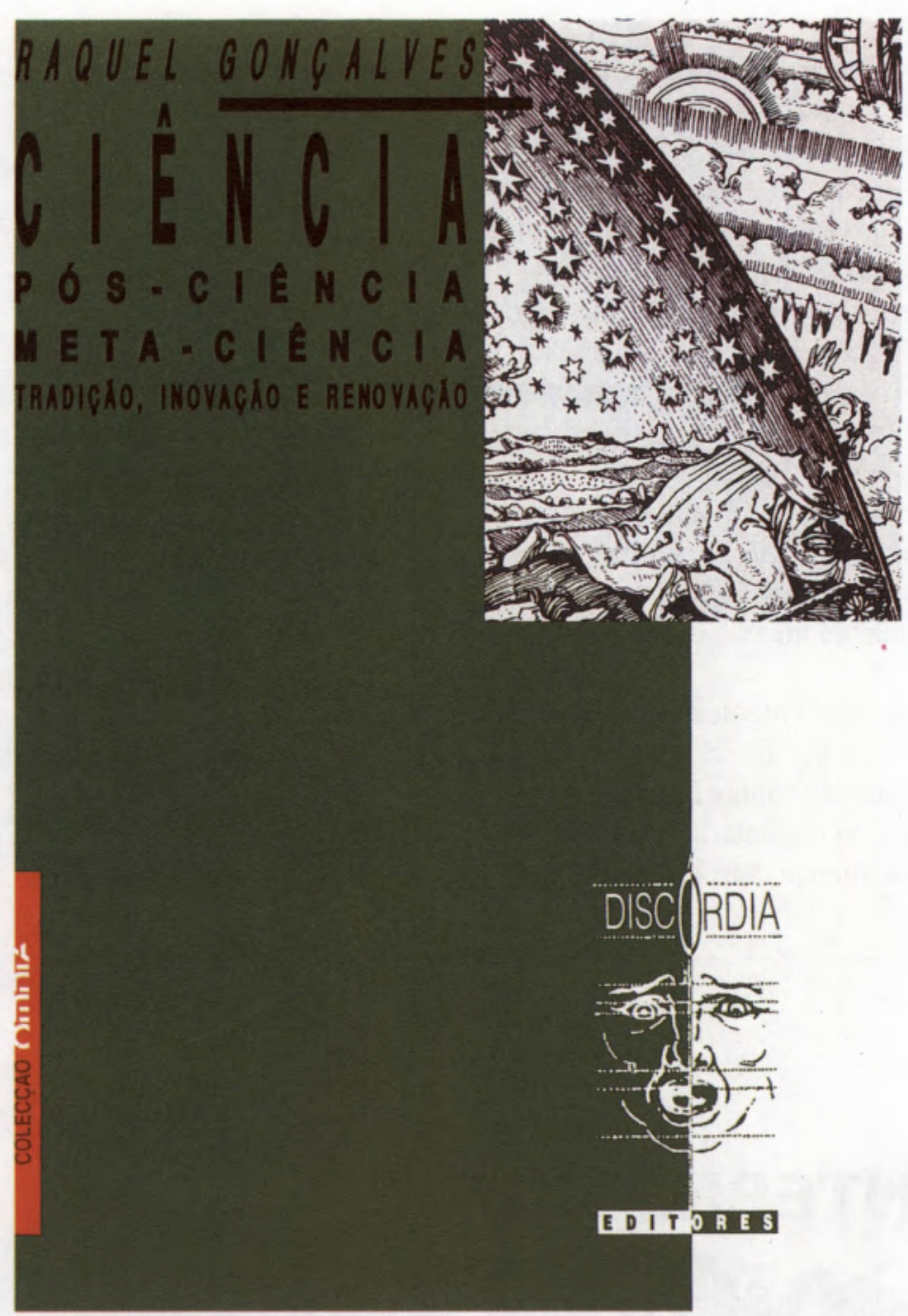

DISCÓRDIA, imagem e exemplo do contraditório, assume o elogio do conflito e a recusa do consenso. Porque no mundo do complexo e do excesso de informação, a comunicaçăo pode ser, em milhares de bits, uma só frase, uma só palavra, urge procurar em cada coisa o seu oposto, gerir a mudança, resolver contradiçōes sem conciliar os contrários, viver os saberes que aspiram à sabedoria. Caminho para a Discórdia.

Número dois da Colecção OMNIA, editado por Discórdia Editores.

Nome

Morada

Sou sócio da SPQ, e desejo receber um exemplar do livro Ciência, Pós-Ciência, Meta-Ciência, com 10\% de desconto sobre o preço de capa, pará o que junto envio o cheque $\mathrm{n}^{\circ}$ do Banco

no valor de 1.575\$00, em nome de Discórdia Editores Lda., Av. de Roma, $93 \mathrm{c} / \mathrm{v}$ Esq., 1700 Lisboa. 